\title{
Cardiorespiratory health and body composition of type 2 diabetics' patients: Effect of a program of adapted physical activity
}

\author{
Teddy Bofosa ${ }^{1,2}$, Eric Kam ${ }^{3}$, Betty Miagindula ${ }^{1,2}$, Donnell Muela ${ }^{1,2}$, Constant \\ Nkiama $^{1,2}$, François $\mathrm{Njimbu}^{2}$ \\ ${ }^{1}$ Department of Physical Medicine and Rehabilitation, Kinesiology Service, University Clinics of Kinshasa, Faculty of Medicine, \\ University of Kinshasa, Democratic Republic of Congo. \\ ${ }^{2}$ Laboratoire de Fitness Médical et Exercice Fonctionnel, Department of Physical Medicine and Rehabilitation, University Clinics of \\ Kinshasa, Faculty of Medicine, University of Kinshasa, Democratic Republic of Congo. \\ ${ }^{3}$ Department of Physical Medicine and Rehabilitation, Physiotherapy Service, University Clinics of Kinshasa, Faculty of Medicine, \\ University of Kinshasa, Democratic Republic of Congo.
}

\begin{abstract}
The Aim of this study is to verify the effects of adapted physical activity on the cardiorespiratory health and body composition of obese diabetic patients. Thirtytwo type 2 diabetes (T2D) patients (11 men, 21 women), aged 39-70 years, were randomly divided into two groups according to body mass index, group 1: 20 overweight subjects $(\mathrm{BMI}<30)$ and group 2: 12 obese subjects (BMI> 30) undergoing a program Adapted physical activity of moderate intensity to severe during 3 months at the rate of 3 sessions of one hour per week. The paired student's t-test was used to evaluate the effect of the intervention program on the 6-minute walk test, arterial blood pressure, heart rate, weight, waist circumference, total fat, and visceral and lean mass. After 3 months of the practice of adapted physical activities, we observed significant changes in their resting heart rate of $-6.06 \mathrm{bpm}(\mathrm{p}<0.05)$, systolic blood pressure of $-7.8 \mathrm{mmHg}(\mathrm{p}<0.05)$, fasting blood glucose of $86.68 \mathrm{mg} / \mathrm{dl}(\mathrm{p}<0.05)$, maximum oxygen consumption of $+6.13 \mathrm{ml} / \mathrm{kg} / \mathrm{min}(\mathrm{p}<0.05)$, total fat of $-5.89 \%(\mathrm{p}<0.05)$, weight of $-8.27 \mathrm{~kg}(\mathrm{p}<0.05)$, body mass index of $-5.17 \mathrm{~kg} / \mathrm{m} 2$ $(\mathrm{p}<0.05)$ and waist circumference of $-5.66 \mathrm{~cm}(\mathrm{p}<0.05)$ and their muscular percentage increased significantly by + 9.17\%. Regular physical activity allows type 2 diabetics patients to improve their cardiorespiratory fitness and change their body composition.
\end{abstract}

Keywords. Adapted physical activities, body composition, cardiorespiratory health, type 2 diabetic patient.

\section{Introduction}

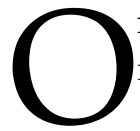
nce the affections of developed and industrialized countries, non-communicable diseases will become a major public health problem after 2020 in sub-Saharan Africa. One of the reasons for this is exposure to the various modifiable risk factors of the environment: sedentary lifestyle, inappropriate meals, excess alcohol, smoking, fiber deficiency, potassium, calcium and magnesium (UN General Assembly, 2011; WHO, 2011).

The prevalence of T2D has increased continuously by $6 \%$ per year between 2000 and 2009 according to data from the National Institute of Health Surveillance (INVS) (WHO, 2011). This growth is expected to continue, due to an aging population, an increase in the life expectancy of people with diabetes, but also an increase in the prevalence of obesity and a sedentary lifestyle, the main causes of T2D. Patients with T2D are becoming younger age. This is a real public health problem (Webber, 2009; Barr et al., 2005; Gaede et al., 2008; Lipscombe \& Hux, 2007).

A surveillance survey, using the WHO STEPS instrument (WHO, 2010), on chronic disease risk factors was conducted in Kinshasa, capital of the Democratic Republic of Congo in 2005. The 3 steps of the SETPS method were completed. In STEP1, sociodemographic and behavioral information was collected. In STEPS 2, physical measurements such as height, weight and blood pressure were taken. This STEPS [Kinshasa / DRC] survey focused on the general population, targeting adults aged 15 and

Received: June 29, 2018 - Accepted: October 28, 2018 - Published: December 30, 2018

To cite this article: Bofosa T, Kam E, Miagindula B, Muela D, Nkiama C, Njimbu F. Cardiorespiratory health and body composition of type 2 diabetics' patients: Effect of a program of adapted physical activity. Turk J Kinesiol, 2018; 4(4): 118-124.

$\bigotimes$ T. Bofosa, e-mail; bofosa.linkoko@unikin.ac.cd DOI: 10.31459/turkjkin.439129 
over. The results of this study showed that in the city of Kinshasa, in adults over the age of 15, the prevalence of arterial hypertension is $11 \%$ and that of diabetes is $15.5 \%$ (Longo-Mbenza et al., 2000; Bieleli et al., 2000).

Aerobic exercise is known to manage glycaemia control and cardiovascular risk factors. It has also beneficial effects for metabolic profile in patients with T2D ( $\mathrm{Ng}$ et al., 2010). Resistance training improves muscular strength and endurance, enhances flexibility and body composition, and decreases the risk of cardiovascular disease (Albright et al., 2000).

Moderate or intense physical activity and cardiorespiratory training are associated with significant reductions in morbidity and mortality, both in men and women, in both type 1 and type 2 diabetes (Chudyk \& Petrella, 2011).

The practice of regular physical exercise is considered the cornerstone of diabetes treatment (Colberg et al., 2011).

Studies are accumulating on the proof of the effectiveness of non-drug therapies, of which adapted physical activity is part, in primary prevention as well as in secondary prevention. However, the application of such therapies requires the patient to be an actor of his health and imposes on him in the long term a change in his behavior (Snowling \& Hopkins, 2006).

We noted the absence of the practice of adapted physical activities in centers for the care of diabetic patients in the Democratic Republic of Congo. This motivated us to introduce an adapted physical activity program as well to evaluate its contribution to the cardiorespiratory health and body composition of these patients.

\section{Methods}

In the present study, we opted for the experimental method and conducted a longitudinal study which consisted in following the evolution of the cardiorespiratory parameters (heart rate, systolic and diastolic blood pressure, $\mathrm{VO}_{2} \max$ ) and body composition of type 2 diabetics' patients during the 3 months period from January to the month of March 2018.

The Kingasani Hospital in Kimbanseke commune in Kinshasa served as the framework for this study. We chose the Kingasani Hospital for the following reasons: Firstly: because it abounds in his own service specialized in the care of APA and a large number of diabetic patients. Secondly, it is one of the major diabetes care centers in Kinshasa, particularly in the commune of Kingasani, and meets the standards for our scientific research.

\section{Study Group}

Out of a total of 59, only thirty-two (32) type II diabetic patients were selected for the present study. Inclusion criteria were as follows: 1) Established T2D for more than one year duration, 2) Treatment only with oral hypoglycemic agents (not taking insulin), 3) An inactive previous lifestyle, A1c level $<11 \%$, 4) Have a BMI $>25-30 \mathrm{~kg} / \mathrm{m}^{2}$ for overweight subjects and BMI $>30 \mathrm{~kg} / \mathrm{m}^{2}$ for obese subjects, 5) Be on the first and last day of the assessment, 6) Have participated at least $95 \%$ in the program, 7) Accept freely to participate in the study.

Exclusion criteria were BMI $43 \mathrm{~kg} / \mathrm{m}^{2}$, age over 70 years, nephropathy, severe retinopathy and neuropathy, cardiovascular diseases or history of serious cerebrovascular, and severe musculoskeletal problems restricting physical activity.

All diabetic subjects had consented in writing to participate in the study according to the Helsinki Declarations. The information collected from diabetic subjects was kept confidential.

\section{Study Parameters}

In this study we used the following parameters: Socio-demographic: Age, sex; body composition: Weight, height, BMI, total fat, visceral fat and muscle; physiological: Heart rate, blood pressure, $\mathrm{VO}_{2} \max$.

\section{Measurements and Data Collection}

The body composition and cardiorespiratory parameters collected were as follows by the kinesiologist team: Weight $(\mathrm{kg})$ using a SECA brand weigh scale calibrated in kilograms $(\mathrm{kg})$ to 100 grams near; the size $(\mathrm{Cm})$ using a height gauge SECA, these two previous measurements allowed us to calculate the body mass index of diabetic patients according to the formula IMC: mass $(\mathrm{Kg}) / \operatorname{Size}^{2}(\mathrm{~m})$; waist circumference using a metric tape of tailors; the percentages of total, visceral and muscle fats were measured using an Omeron BF-511 brand impedance meter; and the blood pressure ( $\mathrm{mmHg}$ ) using a wrist sphygmomanometer that allows us at the same time 
to determine the Medisana brand resting heart rate; Glycaemia was measured by the biologist physician on an empty stomach using a one touch glucose meter; Cardiorespiratory endurance was measured using a six-minute walk test by the kinesiologist. It consisted of asking the diabetic patient to walk a distance of $20 \mathrm{~m}$ return for 6 minutes, then we measured the distance traveled in meters. . With this distance, we calculated the $\mathrm{VO}_{2}$ max from the equation below: $\mathrm{VO}_{2} \max (1 / \mathrm{min})=0.023 \times$ distance (m) + 5.9 Bellet et al., 2012).

All these measures were taken at Kingasani Hospital center once before the intervention program in January and after the program in March 2018.

\section{Exercise Training Protocol}

Participants exercised three times per week, with training progressing gradually in length and intensity. Heart rate monitors (Polar Electro; Oy, Kempele, Finland) were used to adjust workloads to achieve target heart rate. Participants progressed from 15 to 20 min per session at $60 \%$ of maximum heart rate to $45 \mathrm{~min}$ per session at $75 \%$ of measured maximum heart rate. Exercises period was based on aerobic treadmill endurance exercises (for 20 minutes) and muscle building (for 10 minutes), recovery relaxation exercises (for 5 minutes). These different exercises were practiced with several variants to avoid monotony. The subjects were asked to have sweet eatable or drinkable things and not to use their lunches or medications just before the beginning of training. However, they could supply the water required by their bodies in the middle of the sessions. A personal trainer was present for a minimum of three scheduled sessions weekly at each exercise facility and supervised all exercise programmes. After randomization, he/she met each participant individually at least once a week for 2 weeks, every 1 weeks for the subsequent 1 months, then once a month for the remainder of the programme to ensure appropriate progression through the programme. The personal trainer monitored attendance and contacted the participant if any sessions were missed. After the initial 2 weeks post-randomization, participants were free to attend at times most convenient for them, but they were required to come at least once a week at a time when the personal trainer was present.

\section{Data Analysis}

The data collected was entered using the Microsoft Excel 2013 software and then imported into SPSS software version 21.0 (Statistical Package for Social Sciences). Quantitative variables were presented as mean \pm standard deviation and their extremes in the tables. To check the effects of physical exercises, we used the parametric test of student $t$ that allowed us to make comparisons averages obtained. The statistical test results used were interpreted at the $p$ $<0.05$ significance level for statistical decision making.

\section{Results}

Table 1 shows that subjects over 40 years of age and women were more numerous, and overweight diabetics had a longer duration of illness than obese diabetics.

Table 1

Baseline characteristics of study participants.

\begin{tabular}{lcc}
\hline \multirow{2}{*}{ Variables } & \multicolumn{2}{c}{ Diabetics subjects } \\
\cline { 2 - 3 } & $\begin{array}{c}\text { Overweight } \\
(\mathrm{n}=20)\end{array}$ & $\begin{array}{c}\text { Obese } \\
(\mathrm{n}=12)\end{array}$ \\
\hline Ages $(\mathrm{yrs})$ & & \\
$\leq 40(\%, \mathrm{n})$ & $20 \%(\mathrm{n}=4)$ & $16.6 \%(\mathrm{n}=2)$ \\
$>40(\%, \mathrm{n})$ & $80 \%(\mathrm{n}=16)$ & $83.3 \%(\mathrm{n}=10)$ \\
Men $(\%, \mathrm{n})$ & $30 \%(\mathrm{n}=6)$ & $41.6 \%(\mathrm{n}=5)$ \\
Women $(\%, \mathrm{n})$ & $70 \%(\mathrm{n}=14)$ & $58.3 \%(\mathrm{n}=7)$ \\
Clinical Characteristics & & \\
Duration of Diabetes $(\mathrm{yrs})$ & $10.2 \pm 3.8$ & $9.6 \pm 5.1$ \\
BMI $\left(\mathrm{kg} / \mathrm{m}^{2}\right)$ & $28.4 \pm 1.5$ & $34.2 \pm 4.0$ \\
\hline
\end{tabular}

We observed in the table 2 above those diabetic patients significantly after their intervention program altered their body composition and cardiorespiratory health parameters with the exception of visceral fat and diastolic blood pressure.

The Table 3 shows that overweight subjects except visceral fat and diastolic blood pressure, have improved patients significantly all other parameter after the intervention program.

From Table 4 it can be seen that, with the exception of visceral fat, weight, body mass index and muscle, obese diabetics after the intervention have significantly reduced their total fat and waist 
circumference. Regarding the physiological parameters of obese diabetics' subjects, we show that obese diabetics have statistically significantly improved their systolic blood pressure and blood sugar.

\section{Discussion}

This study a revealed that diabetic patients significantly reduced their total fat, weight, body mass index and waist circumference, however their muscle increased significantly. No statistical difference was observed between visceral fat loss before and after. Diabetes patients as a whole were initially obese and became overweight after our intervention program. This improvement is similar to the findings of Sato (2001) that the practice of physical exercises in obese people and obese patients with type-2 diabetes result in a selective decrease of body fat, leading to weight loss, while causing no changes in lean body mass. Our results are inferior to those found by Yavari et al. (2012) in that these authors combined two type of exercises and followed type 2 diabetics' patients for one years.

\section{Table 2}

Comparison of body composition profile and cardiorespiratory fitness averages across the group $(n=32$, Mean $\pm S D)$.

\begin{tabular}{lccc}
\hline Variables & Before & After & $\mathrm{p}$ \\
\hline Total Fat $(\%)$ & $39.92 \pm 5.7$ & $34.03 \pm 5.52$ & $0.002^{*}$ \\
Visceral Fat $(\%)$ & $13.03 \pm 2.7$ & $9.09 \pm 2$ & 0.08 \\
Muscle (\%) & $20.08 \pm 4.1$ & $29.25 \pm 4.6$ & $0.0001^{*}$ \\
Weight $(\mathrm{kg})$ & $88.83 \pm 7.73$ & $80.56 \pm 7.77$ & $0.0001^{*}$ \\
BMI $\left(\mathrm{kg} / \mathrm{m}^{2}\right)$ & $31.88 \pm 4.3$ & $26.71 \pm 3.59$ & $0.003^{*}$ \\
Waist $(\mathrm{cm})$ & $106.53 \pm 9.81$ & $99.87 \pm 9.41$ & $0.006^{*}$ \\
Heart Rate (bpm) & $96.21 \pm 8.5$ & $90.15 \pm 8.2$ & $0.003^{*}$ \\
SBP (mmHg) & $131.81 \pm 9.4$ & $123.96 \pm 9.8$ & $0.001^{*}$ \\
DBP (mmHg) & $88.43 \pm 2.7$ & $85.03 \pm 2.9$ & 0.06 \\
Blood Glucose (mg/dl) & $218.43 \pm 47.7$ & $131.75 \pm 40.1$ & $0.0001^{*}$ \\
VO 2 Max (ml/kg/min) & $24.9 \pm 5.1$ & $31.03 \pm 6.4$ & $0.0001^{*}$ \\
\hline${ }^{*} p<.05$, BMI: Body Mass Index, SBP: Systolic blood pressure, DBP: Diastolic pressure.
\end{tabular}

Table 3

Comparison of body composition profile and cardiorespiratory fitness averages of overweight diabetics $(n=20)$.

\begin{tabular}{lccc}
\hline Variables & Before & After & $\mathrm{p}$ \\
\hline Total Fat (\%) & $36.1 \pm 3.8$ & $30 \pm 4.1$ & $0.004^{*}$ \\
Visceral Fat (\%) & $12.9 \pm 3.5$ & $7.2 \pm 2.1$ & $0.0001^{*}$ \\
Muscle (\%) & $21.1 \pm 3.2$ & $29 \pm 4.1$ & $0.0001^{*}$ \\
Weight $(\mathrm{kg})$ & $82.8 \pm 8.5$ & $76 \pm 9.2$ & $0.002^{*}$ \\
BMI $\left(\mathrm{kg} / \mathrm{m}^{2}\right)$ & $28.4 \pm 1.5$ & $24.2 \pm 1.2$ & $0.003^{*}$ \\
Waist $(\mathrm{cm})$ & $103.3 \pm 9.3$ & $97.7 \pm 8.4$ & $0.0001^{*}$ \\
Heart Rate $(\mathrm{bpm})$ & $94.3 \pm 7.8$ & $88.6 \pm 8$ & $0.0001^{*}$ \\
SBP $(\mathrm{mmHg})$ & $131.8 \pm 8.1$ & $124.6 \pm 8.9$ & $0.0001^{*}$ \\
DBP $(\mathrm{mmHg})$ & $88.1 \pm 3.06$ & $84.8 \pm 3.2$ & 0.091 \\
Blood Glucose (mg/d) & $188.1 \pm 32.04$ & $118.9 \pm 31.95$ & $0.0001^{*}$ \\
VO ${ }_{2}$ Max (ml/kg/min) & $25.6 \pm 5.3$ & $32.8 \pm 7.3$ & $0.007^{*}$ \\
\hline${ }^{*} p<.05$ & & &
\end{tabular}


Table 4

Comparison of body composition profile means of obese diabetics $(n=12)$.

\begin{tabular}{lccc}
\hline Variables & Before & After & $\mathrm{p}$ \\
\hline Total Fat $(\%)$ & $42 \pm 5.8$ & $35.8 \pm 5.5$ & $0.0001^{*}$ \\
Visceral Fat (\%) & $13.3 \pm 2.1$ & $11.1 \pm 2$ & 0.51 \\
Muscle (\%) & $19.5 \pm 5.4$ & $23.3 \pm 5.42$ & 0.22 \\
Weight $(\mathrm{kg})$ & $86.6 \pm 7.3$ & $81.4 \pm 7.2$ & $0.003^{*}$ \\
BMI $\left(\mathrm{kg} / \mathrm{m}^{2}\right)$ & $34.2 \pm 4$ & $30.6 \pm 3.4$ & 0.47 \\
Waist $(\mathrm{cm})$ & $107 \pm 10.5$ & $103.3 \pm 10.3$ & $0.02^{*}$ \\
Heart Rate $(\mathrm{bpm})$ & $98 \pm 9.6$ & $94.3 \pm 8.5$ & 0.067 \\
SBP $(\mathrm{mmHg})$ & $132.3 \pm 11.9$ & $126 \pm 11.7$ & $0.0001^{*}$ \\
DBP $(\mathrm{mmHg})$ & $88.5 \pm 2.6$ & $85.2 \pm 2.7$ & 0.09 \\
Blood Glucose $(\mathrm{mg} / \mathrm{dl})$ & $234.2 \pm 49.9$ & $140.9 \pm 44.2$ & $0.002^{*}$ \\
VO 2 Max $(\mathrm{ml} / \mathrm{kg} / \mathrm{min})$ & $23.9 \pm 4.4$ & $27.6 \pm 4.9$ & 0.842 \\
\hline$* p .05$ & & &
\end{tabular}

With respect to the cardiorespiratory health parameters of diabetic patients, this study showed that they statistically significantly modified their resting heart rate, systolic blood pressure, fasting blood glucose, maximum oxygen consumption. Diastolic blood pressure did not change significantly after the intervention program. Physical activity affects physical fitness by improving cardiac and respiratory functions, including increasing $\mathrm{VO}_{2} \max$ by $11,8 \%$ (Inserm, 2008).

Meta-analyses and other studies have demonstrated that aerobic and resistance exercise each improves glycaemic control in people with this condition (Balducci et al., 2010).

A MEDLINE-type research conducted by Grassi et al. (1992) using the arsenal anti hypertension (HTA) key words and exercises, teaches us that more than 1,500 articles were written on the subject over the past 20 years (Grassi et al., 1992; Balducci et al., 2006; Gordon et al., 2009). All of these articles confirm that regular exercise reduces blood pressure (BP) values by an average of $10 / 7.1$.Or, we know that such an improvement in BP allows to expect a reduction incidence of stroke and myocardial infarction by $34 \%$ and $19 \%$ respectively, which is comparable to the effect of any antihypertensive drug used as monotherapy (Ryan et al., 2001; Baum et al., 2007).

Regarding the body composition of overweight diabetic patients, we found in this study that they significantly decreased their total fat, visceral fat, muscle, weight, body mass index, and waist circumference. A study conducted by Kusuayi et al. (2015) conducted with overweight and obese patients with T2D undergoing a physical exercise program based on aerobic treadmill endurance exercises and muscle building showed a significant decrease in body mass index of $4.9 \mathrm{Kg} / \mathrm{m}^{2}$ compared to the group average of $34.6 \mathrm{Kg} / \mathrm{m}^{2}$ before against $29.7 \mathrm{Kg}$ $/ \mathrm{m}^{2}$ after the physical activity program (Kusuayi et al., 2015).

The greater the energy expenditure caused by physical activity, the greater the weight loss (Aljasir et al., 2010).

The cardiorespiratory health parameters: heart rate, systolic blood pressure, glycaemia, maximum oxygen of overweight diabetic patients were significantly modified after the physical activity intervention program. We also observed no statistically significant difference in diastolic blood pressure after the intervention program.

Exercise training improves glycemic control, body composition, cardiorespiratory fitness, cardiovascular risk, physical functioning and wellbeing in patients with T2D or pre-diabetes (Marwick et al., 2009; Snowling \& Hopkins, 2006).

A systematic review and meta-analysis showed that supervised exercise programs incorporating aerobic or resistance training improved blood glucose control in adults with type 2 diabetes, whether a diet was part of the program or no (Gordon et al., 2008). 
Véronique Perrault's (2011) meta-analyzes indicate that by training 3 to 5 times a week for 4 months, at a rate of 20 to 60 minutes per training session, a decrease of -7.6 to 11 can be obtained. 1 $\mathrm{mmHg}$ systolic pressure; - 6.7 to $7.6 \mathrm{mmHg}$ diastolic pressure. These reductions compare favorably with what is achieved with some antihypertensive drugs.

Obese diabetics' patients have significantly reduced their total fat, weight and waistline after the intervention program, while other parameters have not been significantly modified including visceral fat, body mass index and muscle mass. Physiologically, this study shows that obese diabetics' patients significantly altered their systolic blood pressure, glycaemia while the resting heart rate, maximum oxygen consumption and diastolic blood pressure did not undergo any modifications statistically significant. Our results were different to those found by Perkins BA, Riddell MC, 2006 who said that physical exercise increases the capacity of oxygen consumption by the organism and because of this the glycogen burns aerobically (it burns therefore thanks to the oxygen brought by the blood to the cells) (Perkins \& Riddell, 2006). In large cohort studies of people with type 2 diabetes, regular physical activity or moderate or intense cardiorespiratory training were associated with $39 \%$ decreases at $70 \%$ of cardiovascular mortality and overall mortality over 15 to 20 years of follow-up (Guelfi et al., 2007; Fahey et al., 2012).

\section{Conclusion}

The regular practice of adapted physical activity allows diabetic patients to improve not only their cardiorespiratory health but also their body composition.

\section{Conflicts of interest}

The authors declare that they have no conflicts of interest in relation to this article.

\section{Acknowledgments}

Our thanks to the authorities of Kingasani Hospital for allowing us to conduct our research within this institution and diabetic subjects to have agreed to work with us.

\section{References}

Albright A, Franz M, Hornsby G, Kiriska A, Marrero D, Urlich I, Verity LS. Exercise and type diabetes. Med Sci Sports Exerc, 2000; 32: 1345-1360.

Aljasir B, Bryson M, Al-Shehri B. Yoga practice for the management of type II diabetes mellitus in adults: a systematic review. J Evid Based Complementary Altern Med, 2010; 7:399-408.

Balducci S, Iacobellis G, Parisi L, Di Biase N, Calandriello E, Leonetti F, Fallucca F. Exercise training can modify the natural history of diabetic peripheral neuropathy. J Diabetes Complications, 2006; 20: 216-223.

Balducci S, Zanuso S, Nicolucci A, De Feo P, Cavallo S, Cardelli P, Fallucca S, Alessi E, Fallucca F, Pugliese G. Effect of an intensive exercise intervention strategy on modifiable cardiovascular risk factors in subjects with type 2 diabetes mellitus: a randomized controlled trial: the Italian Diabetes and Exercise Study (IDES). Arch Intern Med, 2010; 170: 1794-1803.

Barr E, Magliano D, Zimmet P, Polkinghorne KR, Atkins RC, Dunstan DW, Murray SG, Shaw JE. AusDiab 2005: The Australian Diabetes, Obesity and Lifestyle Study, 2006. http://www.diabetes.com.au/pdf/AUSDIAB_Repor t_Final.pdf (accessed April 7, 2011)

Baum K, Votteler T, Schiab J. Efficiency of vibration exercise for glycemic control in type 2 diabetes patients. Int J Med Med Sci, 2007; 4: 159-163.

Bellet RN, Adams L, Morris NR. The 6-minute walk test in outpatient cardiac rehabilitation: Validity, reliability and responsiveness a systemic review. Physiotherapy, 2012; 98: 277-286.

Bieleli E, Moswa JL, Ditu mpandamadi S, Kandjungu K, Mulumba M. Prévalence du diabète sucré au sein de la population de Kinshasa. Congo Médical, 2000; 2(15): 1055-1061.

Chudyk A, Petrella RJ. Effects of exercise on cardiovascular risk factors in type 2 diabetes: a meta-analysis. Diabetes Care, 2011; 34: 1228-1237.

Colberg SR, Sigal RJ, Fernhall B, Regensteiner JG, Blissmer BJ, Rubin RR, Chasan-Taber L, Albright AL, Braun B. Exercise and type 2 diabetes: The American College of Sports Medicine and the American Diabetes Association: Joint Position Statement. Diabetes Care, 2010; 33: 147-167.

Gaede P, Lund-Andersen H, Parving HH, Pedersen O. Effect of a multifactorial intervention on mortality in type 2 diabetes. N Engl J Med, 2008; 358: 580-591.

Fahey AJ, Paramalingam N, Davey RJ, Davis EA, Jones TW, Fournier PA. The effect of a short sprint on post- 
exercise whole body glucose production and utilization rates in individuals with type 1 diabetes mellitus. J Clin Endocrinol Metab, 2012; 97: 41934200 .

Gordon BA, Benson AC, Bird SR, Fraser SF. Resistance training improves metabolic health in type 2 diabetes: A systematic review. Diabetes Res Clin Pract, 2009; 83: 157-175.

Gordon LA, Morrison EY, McGrowder DA, Young R, Fraser YTP, Zamora EM, Alexander-Lindo RL, Irving RR. Effect of exercise therapy on lipid profile and oxidative stress indicators in patients with type 2 diabetes. BMC Complement Altern Med, 2008; 8: 21.

Grassi G, Servalle G, Calhoun D, Bolla GB, Mancia G. Physical exercise in essential hypertension. Chest, 1992; 101: 312.

Guelfi KJ, Ratnam N, Smythe GA, Jones TW, Fournier PA. Effect of intermittent high-intensity compared with continuous moderate exercise on glucose production and utilization in individuals with type 1 diabetes. Am J Physiol Endocrinol Metab, 2007; 292: E865-70.

Hu G, Jousilahti P, Barengo NC, Qiao Q, Lakka TA, Tuomilehto J. Physical activity, cardiovascular risk factors, and mortality among Finnish adults with diabetes. Diabetes Care, 2005; 28: 799-805.

Inserm. Activité physique: Contextes et effets sur la santé, 2008.

Kusuayi MG, Bofosa LT,Kiana NN,Muela MD, Miangindula MB, Nkiama EC. Effets des execices physiques de l'endurance aérobie et de renforcement musculaire sur la composition corporelle des femmes obèses. Annales Africaine de Medédecine, 2015; 8(4): 2142-2148.

Lipscombe LL, Hux JE. Trends in diabetes prevalence, incidence, and mortality in Ontario, Canada 19952005: a population-based study. Lancet, 2007; 369: 750-756.

Longo-Mbenza B, Tonduangu K, Muyeno K, Phanzu M, Kebolo Baku A, Muvova D, Lelo T, Odio W, Lukoki L, Bikangi Nkiabungu F, Kilembe M, Tshiamala P, Katalay L, Mwema M, Muyembe T. Predictors of stroke-associated mortality in Africans. Revue d' Epidemiologie et Santé Publique, 2000; 48: 31-39.
Marwick TH, Hordern MD, Miller T, Chyun DA, Bertoni AG, Blumenthal RS, Philippides G, Rocchini A. Exercise training for type 2 diabetes mellitus: impact on cardiovascular risk: a scientific statement from the American heart association. Circulation, 2009; 119: 3244-3262.

Ng CLW, Goh SY, Malhotra R, Ostbye T, Tai ES. Minimal difference between aerobic and progressive resistance exercise on metabolic profile and fitness in older adults with diabetes mellitus: a randomized trial. J Physiother, 2010; 56: 163-170.

Perkins BA, Riddell MC. Type 1 diabetes and exercise: Using the insulin pump to maximum advantage. Can J Diabetes, 2006; 30: 72-79.

Ryan AS, Hurlbut DE, Lott ME, Ivey FM, Fleg J, Hurley BF, Goldberg AP. Insulin action after resistive training in insulin resistant older men and women. J Am Geriatr Soc, 2001; 49: 247-253.

Sato Y. A Teaching Guide for Therapeutic Exercise in Diabetes Mellitus (Revised 2nd edition), Nankodo, 2001 (in Japanese).

Snowling NJ, Hopkins WG. Effects of different modes of exercise training on glucose control and risk factors for complications in type 2 diabetic patients: a metaanalysis. Diabetes Care, 2006; 29: 2518-2527.

UN General Assembly. Resolution 61/225 World Diabetes Day. Jan 18, 2007. http://www.worlddiabetesday. org/files/docs/U4D/UN_Resolution.pdf (accessed April 7, 2011).

Véronique P. Angiotensin receptor blockers and risk of myocardial infarction: meta-analyses and trial sequential analyses of 147020 patients from randomised trials. BMJ, 2011; 342: 2234.

Webber J. Changing epidemiology of obesityimplications for diabetes. In: Obesity and diabetes (Barnett A, Kumar S, eds.) 2nd edition, Oxford: John Wiley and Sons, 2009: 1-12.

WHO. Global status report on noncommunicable diseases 2010. April, 2011. http://www.who.int /nmh/publications/ncd_report2010/en (accessed April 7, 2011).

WHO. Use of glycated haemoglobin (HbA1C) in the diagnosis of diabetes mellitus. 2011. http://www.who.int/diabetes/publications/reporth ba1c_2011.pdf (accessed April 7, 2011). 